\title{
Estrogen and Progesterone Synthesis with Cellular Response in a C57BL/6 Mouse Model of Cuprizone-Induced Demyelination
}

\author{
Mehmet Önder Karayiğit ${ }^{1}$ \& Murat Yarım²
}

\begin{abstract}
Background: Demyelination refers to the degradation or loss of myelin sheath. In demyelination model studies, it has been reported that demyelination is regressed by giving steroid hormones such as estrogen and progesterone. However, there are not many studies investigating the synthesis of these two hormones by the brain during demyelination and remyelination. Neurosteroids are steroid hormones synthesized by the brain independently from peripheral tissues. In this study, it was aimed to have knowledge about the synthesis of these two hormones by the brain in experimentally formed demyelination process in brains of C57BL/6 mice and their role in the cellular response formed in the region.

Materials, Methods \& Results: In the study, 36 C57BL/6 mice were used: 12 mice were fed normal diet for 12 weeks as control group (Group I); 12 of them were fed $0.2 \%$ cuprizone diet for 8 weeks (Group II) and 12 mice were fed normal diet for 4 weeks after feeding cuprizone diet for 8 weeks (Group III). At the end of the experiment, mice were perfused with $4 \%$ paraformaldehyde and brain tissues were blocked in paraffin. $6 \mu$ m-thick section was taken from each block. Sections were stained histologically with LFB staining and immunohistochemically with MBP staining in order to determine the demyelination in sections. All sections were also immunohistochemically stained with GFAP to detect astrocytes, with NG2 to detect young OPCs, with aromatase for estrogen synthesis and with $3 \beta \mathrm{HSD}$ antibodies for progesterone synthesis. At the end of the study, complete myelination was observed in group I, while severe demyelination was determined in group II as a result of blind evaluation of LFB and MBP staining by two pathologists. In group III, demyelination was found to be mild. In immunostaining with GFAP and NG2 antibodies, the number of GFAP and NG2 positive cells in Group II was found to be increased compared to the control group. The difference between these two groups was statistically significant $(P<0.01)$. In group III, the number of GFAP and NG2 positive cells were found to be increased compared to the control group; however, it was found to be lower than that in experimental group II $(P<0.01)$. In immunohistochemical staining with aromatase and 3 $3 \mathrm{HSD}$ antibody, there was no staining observed in the control groups. While an intense staining was observed in experimental group II, fewer glial staining was noticed in experimental group III when compared to the experimental group II. The difference between these two groups was found to be statistically significant $(P<0.01)$.

Discussion: Aromatase is an enzyme that converts testosterone into estrogen. On the other hand, 3ßHSD is an enzyme that converts pregnenolone to progesterone. Expression of aromatase from tissues refers to the synthesis of estrogen and expression of $3 \beta \mathrm{HSD}$ refers to progesterone synthesis. In previous demyelination studies carried out with cuprizone, it has been reported that demyelination is regressed by giving estrogen and progesterone during demyelination. In the presented study, we observed that enzyme levels that catalyze the synthesis of estrogen and progesterone increased during demyelination. In the study, it was determined that estrogen and progesterone levels were increased in the region by enzymes released from the glial cells of the brain as a response to damage formed during demyelination. Interestingly, during the period in which cuprizone was excluded from the diet, it was observed that remyelination began to be formed again and that enzyme levels synthesizing these hormones started to decrease. These results suggested that estrogen and progesterone may be synthesized in the brain after a damage and may contribute to remyelination by initiating a number of cell to cell signaling steps.
\end{abstract}

Keywords: demyelination, cuprizone, aromatase, 3ßHSD, remyelination. 


\section{INTRODUCTION}

Demyelination can occur because of ischemic, infectious and toxic causes. In diseases progressing with demyelination characterized by the loss of oligodendrocytes, demyelination is thought to be associated with oxidative stress, mitochondrial damage and microglial activation $[6,35]$. This can activate astrocytes which can be both beneficial and harmful to the disease process $[4,5,18,33,34,36]$.

When cuprizone was added to the diet of young male mice, it has been seen that demyelination was formed in central nervous system (CNS) and changes were determined in cellular, molecular, biochemical and morphological parameters around the lesions [22]. Following the damage occurred in CNS, some bioactive molecules with local protective effects are expressed from neurons and activated glial cells $[14,17]$. Some of these are neurosteroid hormones synthesized from the brain independently from the gonads and adrenal glands.

Aromatase is an enzyme that catalyzes the synthesis of esrogen from the brain [1,9,32]. 3Beta hydroxysteroid dehydrogenase (3ßHSD) is the enzyme that converts pregnenolone to progesterone. Expression of these two enzymes in the brain indicates the estrogen and progesterone synthesis in the brain [7]. When both estrogen and progesterone are given externally, oligodendroglial and neuronal death is prevented and myelin sheath synthesis is accelerated and the demyelination is regressed $[8,12,26,29,30]$.

With this study, it was aimed to have information about the role of estrogen and progesterone in the cellular response occurred in demyelination process by investigating the expression of neuro steroidogenic enzymes such as aromatase and $3 \beta \mathrm{HSD}$ from glial cells after the brain damage.

\section{MATERIALS \& METHODS}

\section{Animals}

Three-month-old 36 male C57BL/6 mice with an average weight of $25 \pm 5 \mathrm{~g}$ were used in the study. 12 of mice were used as a control group by feeding standard mouse diet for 12 weeks (Group I). 12 mice were fed $0.2 \%$ cuprizone diet for 8 weeks (Group II) and the rest 12 mice were fed $0.2 \%$ cuprizone diet for 8 weeks followed by normal diet for 4 weeks (Group III). Ad libitum access to drinking water was provided to all mice.
At the end of the study, necropsy was conducted to all mice following the cardiac perfusion with $4 \%$ paraformaldehyde under $3 \mathrm{mg} / \mathrm{kg}$ ketamine $\mathrm{HCl}$ anesthesia. After cardiac perfusion, animals' brains were removed and the sections were trimmed passing through the corpus callosum (CC) region. Trimmed brain samples were fixed in $4 \%$ paraformaldehyde solution for $24 \mathrm{~h}$ at $+4^{\circ} \mathrm{C}$, then washed under running water for one day and blocked in paraffin by treating with alcohol-xylol. Subsequently, $6 \mu \mathrm{m}$-thick sections were taken using the Rotary microtome (Leica, RM 2125) ${ }^{1}$.

Luxol-Fast Blue (LFB) staining was performed histochemically to determine demyelination and remyelination in all tissue sections. Immunohistochemical (IHC) staining was performed on the tissues using avidin-biotin immunoperoxidase complex method. All tissue sections were deparaffinized in xylene and then rehydrated in graded alcohols. Then, antigen retrieval was performed for $20 \mathrm{~min}$ at $600 \mathrm{Watt}$ and tissue sections were left to cool for $20 \mathrm{~min}$. For endogenous peroxidase activity, they were kept in a methanol-3\% hydrogen peroxide solution for $15 \mathrm{~min}$. Sections were washed 3 times in phosphate buffer saline (PBS) for 5 min each. All sections were treated with block solution for $10 \mathrm{~min}$ and myelin basic protein (MBP) [Anti MBP antibody, ab7349] $]^{2}$, glial fibrillary acidic protein (GFAP) [Anti GFAP antibody, ab7779] 2, 3ßHSD [Anti 3ßHSD ab65156] ${ }^{2}$, neural glial antigen 2 [Anti NG2 antibody ab81104] ${ }^{2}$ and aromatase [Anti-P450arom antibody AP00001PU-N] $]^{3}$ antibodies were dropped on sections without washing and sections were incubated for $1 \mathrm{~h}$ at room temperature. Following washing, biotin-labeled secondary antibody was dropped on sections and sections were incubated for $30 \mathrm{~min}$ and then washed with PBS 3 times for $5 \mathrm{~min}$. Then, they were incubated with streptavidin-peroxidase [Zymed, Histostain Plus Kit] ${ }^{4}$ enzyme for $30 \mathrm{~min}$. At the end of this period, the tissues were again washed 3 times with PBS for 5 min.

Finally, controlled staining was applied to sections with 3-amino-9-ethylcarbazole chromogen ${ }^{4}$ under the microscope for $10 \mathrm{~min}$. Counterstaining was performed using Gill's hematoxylin. Sections were closed with water-based adhesive and examined under light microscope [Nikon, YS 100] .

\section{Assessment of demyelination}

Histochemically LFB and immunohistochemically MBP-stained sections were blindly scored from 0 
to 3 by two pathologists. In the control group fed with normal diet, the amount of myelin was expressed as 3 , the amount of mild demyelination as 2 , the amount of severe demyelination as 1 , and the amount complete demyelination as 0 [23].

\section{Cell counting method}

Sections taken passing through the $\mathrm{CC}$ region according to the brain atlas prepared by Harward University for C57BL/6 mice were immunohistochemically stained with GFAP, NG2, Aromatase and $3 \beta \mathrm{HSD}$ antibodies and the whole mentioned region was photographed with Nikon DS Camera ${ }^{10}$. For each antibody, each cell of which cytoplasm was positively stained was counted separately, and the results of all staining methods were evaluated statistically (Table 1).

\section{Statistical analysis}

In the study, differences between the groups were analyzed using one-way analysis of variance technique according to the organs. Intergroup differences were investigated using DUNCAN multiple comparison test. In addition, introductory statistics for the groups were listed in Table 1. The results were obtained using SAS [2009] statistical package program.

Table 1. Intergroup differences investigated using DUNCAN multiple comparison test.

\begin{tabular}{ccccc}
\hline Group & GFAP & P450arom & $3 \beta$ HSD & NG2 \\
\hline I (Control) & $23.00 \pm 1.86 \mathrm{c}$ & $0.00 \pm 0.00 \mathrm{c}$ & $0.00 \pm 0.00 \mathrm{c}$ & $10.25 \pm 0.75 \mathrm{c}$ \\
II & $166.16 \pm 10.37 \mathrm{a}$ & $33.91 \pm 2.06 \mathrm{a}$ & $25.33 \pm 2.00 \mathrm{a}$ & $42.50 \pm 17.0 \mathrm{a}$ \\
III & $84.75 \pm 4.42 \mathrm{~b}$ & $13.41 \pm 1.47 \mathrm{~b}$ & $9.66 \pm 1.32 \mathrm{~b}$ & $18.50 \pm 1.89 \mathrm{~b}$ \\
\hline
\end{tabular}

$\mathrm{a}, \mathrm{b}, \mathrm{c}$ the difference between group averages is statistically significant $(P<0.01)$. Average values obtained from median kind.

\section{RESULTS}

In the study, the amount of myelin obtained from the staining with LFB (Figure 1) and MBP (Figure 2) was evaluated by two pathologists. In the control group, group I, a complete myelination was detected while a severe demyelination was detected in group II, whereas in group III in which cuprizone was excluded from the diet, remyelination was formed and demyelination regressed to mild level.

In addition, in IHC staining performed with GFAP (Figure 3) to determine astrocytes and with NG2 (Figure 4) to determine young oligodendrocyte precursor (OPC) cells, low number of cells were positive stained in Group I which was the control group, whereas the number of positive stained cells were found to increase significantly in group II in which severe demyelination was detected. In the 3rd group in which demyelination regressed after exclusion of cuprizone from the ration and remyelination was formed, the number of positive stained cells was found to be higher than that in control group but less than that in the group II in which demyelination was formed $(P<0.01)$.

In IHC staining with aromatase (Figure 5) and $3 \beta \mathrm{HSD}$ (Figure 6) antibodies, there was no positive staining detected in glial cells in control group. In the group II in which demyelination occurred, positive stained glial cells were observed whereas, in the group III in which remyelination was formed, the number of positive stained cells was found to decrease significantly compared to group II $(P<0.01)$.

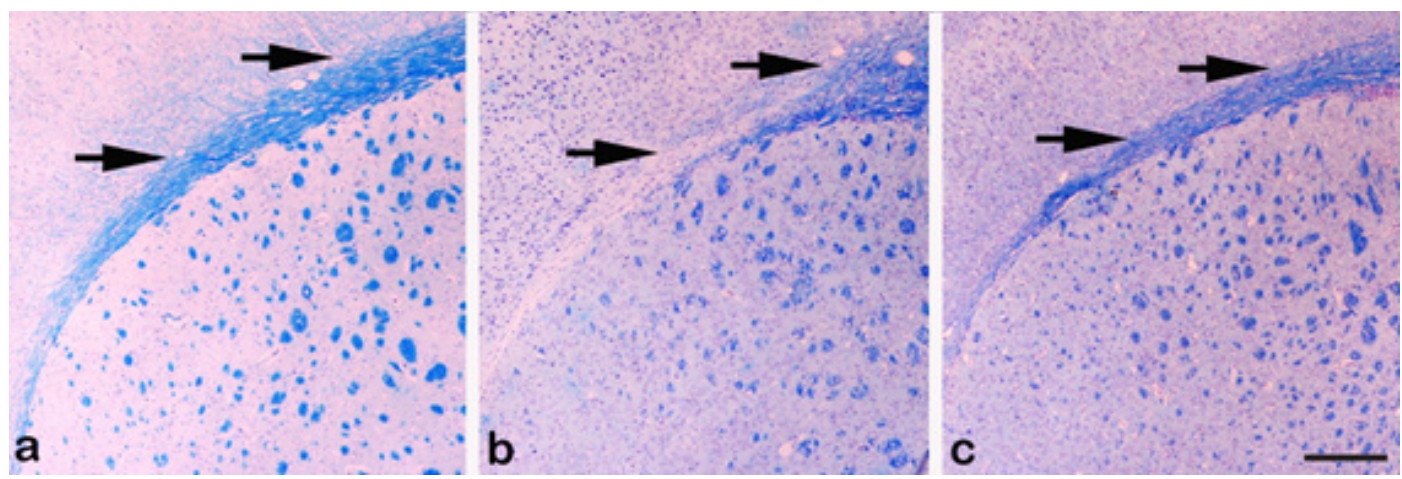

Figure 1. a- Complete myelination in CC in control group (arrows). [LFB, Bar= $100 \mu \mathrm{m}]$. b- Severe demyelination in CC in group II (arrows). [LFB, Bar= $100 \mu \mathrm{m}$ ]. c- Mild demyelination in CC in group III (arrows). [LFB, Bar= $100 \mu \mathrm{m}]$. 


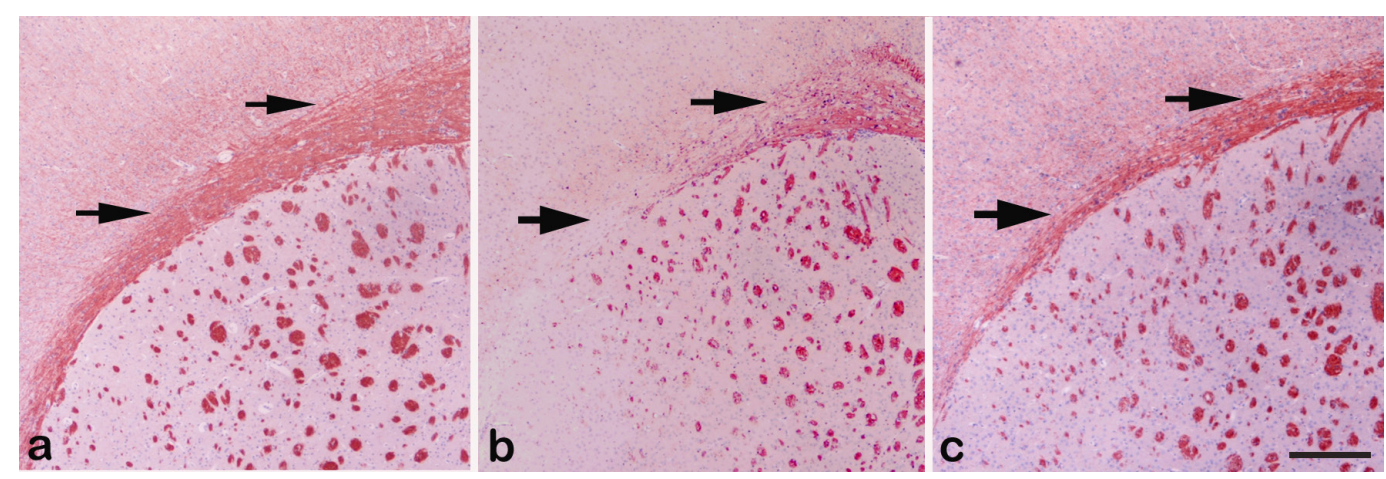

Figure 2. a- Severe expression for MBP antibody in CC in control group (arrows). [IHC, Bar= $100 \mu \mathrm{m}]$. b- Mild expression for MBP antibody in CC in group II (arrows). [IHC, Bar= $100 \mu \mathrm{m}$ ]. c- Moderate expression for MBP antibody in group III in CC (arrows). [IHC, Bar= $100 \mu \mathrm{m}]$.

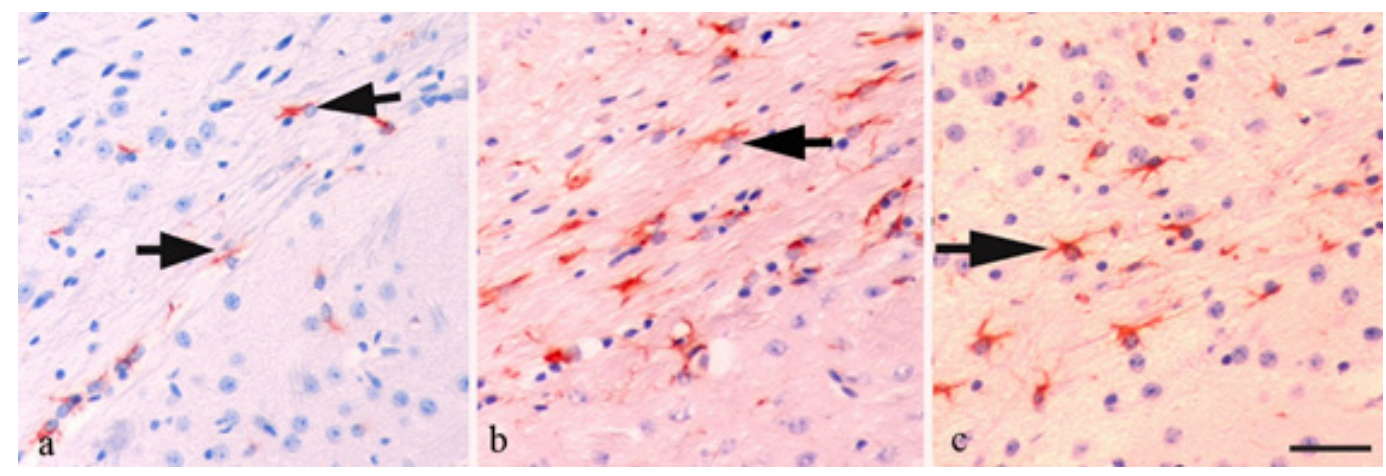

Figure 3. a- Mild expression for GFAP antibody in CC in control group (arrows). [IHC, Bar= $25 \mu \mathrm{m}]$. b- Severe expression for GFAP antibody in CC in group II (arrow). [IHC, Bar= $25 \mu \mathrm{m}$ ]. c- Moderate expression for GFAP antibody in CC in group III (arrow). [IHC, Bar= $25 \mu \mathrm{m}]$.

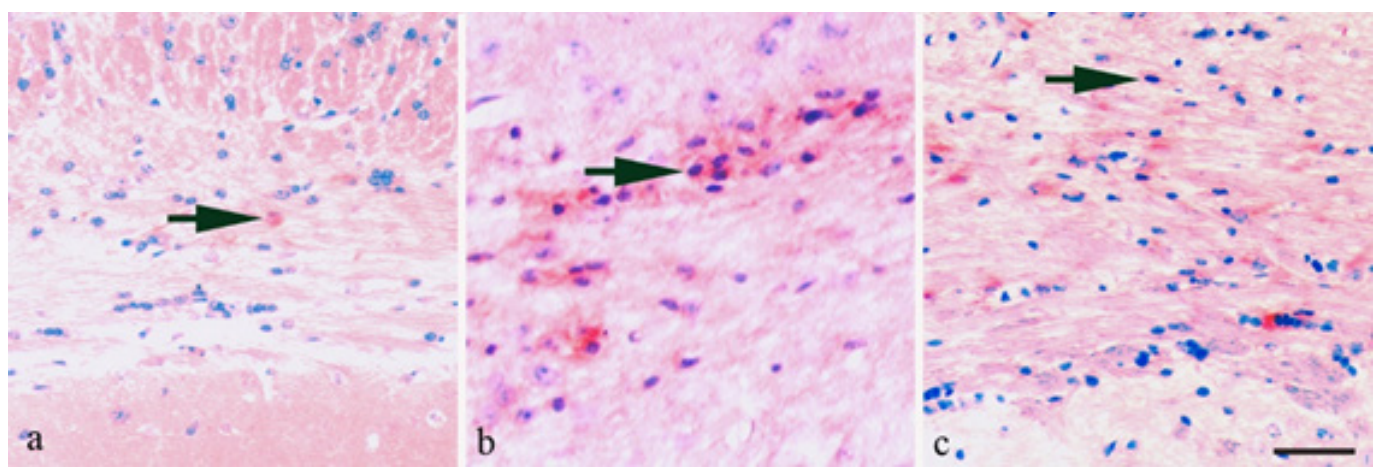

Figure 4. a- Mild expression for NG2 antibody in CC in control group (arrow). [IHC, Bar= $25 \mu \mathrm{m}$ ]. b- Severe expression for NG2 antibody in CC in group II (arrow). [IHC, Bar $=25 \mu \mathrm{m}$ ]. c- Moderate expression for NG2 antibody in CC in group III (arrow). [IHC, Bar= $25 \mu \mathrm{m}]$.

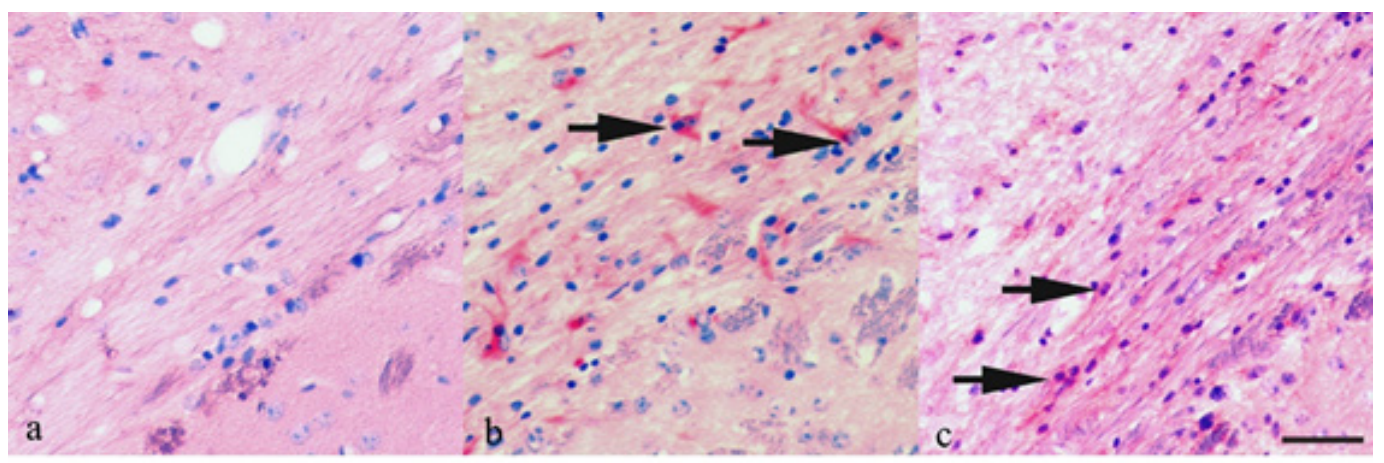

Figure 5. a- Negative expression for aromatase antibody in CC in control group. [IHC, Bar $=25 \mu \mathrm{m}$ ]. b- Severe expression for aromatase antibody in CC in group II (arrows). [IHC, Bar= $25 \mu \mathrm{m}$ ]. c- Mild expression for aromatase antibody in CC in group III (arrows). [IHC, Bar $=25 \mu \mathrm{m}]$. 


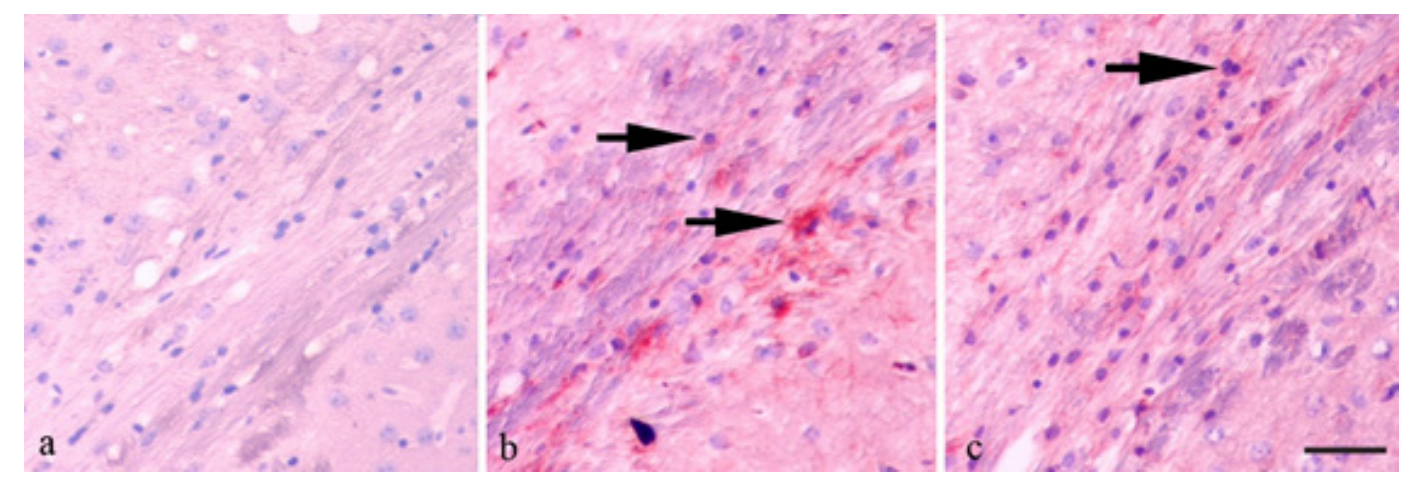

Figure 6. a- Negative expression for $3 \beta \mathrm{HSD}$ antibody in $\mathrm{CC}$ in control group. [IHC, Bar $=25 \mu \mathrm{m}$ ]. b- Severe expression for $3 \beta \mathrm{HSD}$ antibody in CC in group II (arrows). [IHC, Bar= $25 \mu \mathrm{m}$ ]. c- Mild expression for $3 \beta \mathrm{HSD}$ antibody in CC in group III (arrow). [IHC, Bar $=25 \mu \mathrm{m}]$.

\section{DISCUSSION}

Aromatase is the enzyme that catalyzes the synthesis of estrogen [1] The expression of aromatase in the brain is very low under normal conditions and is limited to neurons $[13,19,20]$. However, it has been found that the expression of aromatase from neurons increases, thus the level of local estrogen increases after experimentally formed neuronal damage $[8,9,24]$. The investigations conducted have suggested that the increase in estrogen level associated with neuronal damage may be a protective feature specific to brains of vertebrates and may be an important component in the initiation of a neuronal response to damage $[8,9,24]$.

Progesterone has been reported to play an important role in regeneration of neurons and myelin formation $[25,37]$. $3 \beta \mathrm{HSD}$ catalyzes the progesterone synthesis and expression of $3 \beta \mathrm{HSD}$ from tissues indicates progesterone synthesis in the region [11].

In the study conducted by Taylor et al. [31] C57BL/6 mice were fed cuprizone diet and demyelination was formed, while estrogen was given as a subcutaneous implant to another group at the same time. They have found mature oligodendrocyte loss, microglial accumulation, and decreased IGF-1 and TNF release in the group in which implant was applied compared to the group in which implant was not applied. Besides prevention of apoptosis of oligodendrocytes by giving estrogen externally, they have found that IGF-1 release can also be reduced suppressing microglia and astrocyte activation, thus demyelination can partially be prevented by the reduction of harmful substances such as TNF released from these cells [31].

Another study has reported that while forming demyelination with cuprizone in C57BL/6 mice, giv- ing progesterone with estrogen externally at the same time was found to be more beneficial than the effect of estrogen alone on demyelination [23]. Contrary to Taylor et al. [31], Peter et al. [23] have emphasized that co-administration of estrogen and progesterone increases the number of astrocytes and demyelination can be greatly inhibited by stimulation of IGF-1 release from glial cells. These two studies conducted are the closest ones to the presented study in terms of animal used and demyelination model. However, unlike these two studies, estrogen and progesterone were not externally administered during demyelination process but it is thought that aromatase and 3 $\beta \mathrm{HSD}$ enzymes were expressed from the astrocytes in the region, and accordingly, progesterone and estrogen were synthesized in the damaged region. There are studies showing that the level of aromatase expressed from the neurons in the region increases after neuronal damage $[8,9,24]$. However, there is one study in which aromatase is expressed from glial cells after demyelination [34].

Aromatase enzyme expression from glial cells increased in demyelination formed during distemper [34]. In the study conducted by Yarim et al. [34] they have found that aromatase expression was very low from astrocytes in the cerebellum of dogs, whereas aromatase expression of astrocytes in demyelination region in cerebellum of animals with distemper increased. In presented study, aromatase expression was observed in the group in which demyelination occurred, while the aromatase expression from glial cells was not observed in the $\mathrm{CC}$ region of brain of mice in control group. It is believed that the difference observed in control group animals in two mentioned studies are likely to vary according to the animal species or the different regions of the CNS. 
Although there is no study showing that progesterone is synthesized in the brain during demyelination, there are studies reporting that the externally given progesterone regresses demyelination $[23,25,34,37]$. In the study, it was found that young OPC and astrocytes in the region proliferated besides estrogen and progesterone synthesis during demyelination [23]. Although the pathogenesis was not clear, it is thought that the level of these two neurosteroid hormones may increase in order to protect the brain during demyelination and that cellular proliferation may initiate the signaling stages for remyelination. Because in the study, when the cuprizone was excluded from the diet, remyelination was formed in the region again and the OPC increase, glial activation and hormone expressions began to decrease significantly $[8,9,13,19,20,24]$.

These results suggest that damage in the brain can be repaired at a certain level without any treatment or stimulant applied externally when the effect causing damage in the brain is removed. These findings are thought to be important in the brain, which is vital, and does not have regeneration feature. However, this mechanism is complex and full of assumptions. It is a strong assumption that estrogen and progesterone synthesized in response to the damage in the area was the effect initiating remyelination in the study.

It has been reported that CNS cells, especially astrocytes, are important in the MS-related demyelination and remyelination mechanism and demyelination can progress as a result of the increase of inflammatory cytokines released from astrocytes with the proliferation of these cells, and apoptosis of oligodendrocytes because of cuprizone [28]. On the other hand, it has been reported that estrogen stimulates the release of various growth factors from reactivated astrocytes when given externally, and that these growth factors accelerate remyelination by inhibiting oligodendrocyte apoptosis and providing OPC migration to the region with lesion $[8,15,31]$. Estrogen can also stimulate progesterone synthesis from astrocytes by stimulating them $[21,27]$. It is not known which mechanism stimulated the synthesis of aromatase from glial cells in this presented study, however, it is thought that in some way there may be a compensation mechanism in response to demyelination. Aromatase expression from glial cells may have initiated local estrogen production in $\mathrm{CC}$ region of brain. Estrogen synthesis can trigger local synthesis of progesterone from astroglial cells by stimulating their proliferation just as in studies in which estrogen was given externally $[3,11,16,21,27]$.

The results of this study support the hypothesis suggesting that progesterone can regress demyelination by stimulating OPC migration to the region of demyelination and inhibiting oligodendrocyte apoptosis $[9,15,23,28,31]$. Because, in the study, OPC migration was detected with the proliferation of astrocytes in the region of demyelination.

As a result, estrogen and progesterone synthesized with the activation of the protective mechanism during demyelination in the brain may not provide a fast recovery as the estrogen and progesterone given externally. However, knowing the existence of such mechanism can be a step for future studies, and perhaps with more extensive studies, results that can make this mechanism more active in humans and animals before the damage reaches a critical level during diseases characterized with demyelination, can be obtained.

\section{CONCLUSIONS}

Increased expression levels of steroidogenic enzymes such as aromatase and 3 $3 \mathrm{HSD}$ in the glial cells following demyelination could increase estrogen and progesterone and this contribute significantly through regression of the demyelination and progression of the remyelination.

\section{MANUFACTURERS}

${ }^{1}$ Leica. Wetzlar, Germany.

${ }^{2}$ Abcam. Cambridge, UK.

${ }^{3}$ Novus biologicals. Littleton, CO, USA.

${ }^{4}$ Thermo Fisher Scientific. Waltham, MA, USA.

${ }^{5}$ Nikon Imaging Japan Inc.Tokyo, Japan.

Acknowledgements. This research was conducted as a doctoral thesis study at Veterinary Faculty at Ondokuz Mayıs University.

Funding. This research was supported by Ondokuz May1s University as a doctoral thesis project (PYO.VET.1904.09.001).

Declaration of interest. The authors report no conflicts of interest. The authors alone are responsible for the content and writing of the paper.

\section{REFERENCES}

1 Azcoitia I., Sierra A., Veiga S., Honda S., Harada N. \& Garcia-Segura L.M. 2001. Brain Aromatase Is Neuroprotective. Journal of Neurobiology. 47(4): 318-239. 
2 Bruce-Keller A.J., Keeling J.L., Keller J.N., Huang F.F., Camondola S. \& Mattson M.P. 2000. Antinflammatory effects of estrogen on microglial activation. Endocrinology. 141: 3646-3656.

3 Chan J.R., Phillips L.J. \& Glaser M. 1998. Glucocorticoids and progestins signal the initiation and enhance the rate of myelin formation. Proceedings of the National Academy Sciences of the United States of the Americe. 95(18): 10459-10464.

4 Crawford A.H., Stockley J.H., Tripathi R.B., Richardson W.D. \& Franklin R.J.M. 2014. Oligodendrocyte progenitors: Adult stem cells of the central nervous system? Experimental Neurology. 260: 50-55.

5 do Carmo Cunha J., de Freitas B.A.L., de Luca B.A., de Andrade M.S., Gomide V.C. \& Chadi G. 2007. Responses of reactive astrocytes containing S100 protein and fibroblast growth factor- 2 in the border and in the adjacent preserved tissue after a contusion injury of the spinal cord in rats: implications for wound repair and neuroregeneration. Wound Repair and Regeneration. 15(1): 134-146.

6 Fischer M.T., Wimmer I., Hoftberger R., Gerlach S., Haider L., Zrzavy T., Hametner S., Mahad D., Binder C.J., Krumbholz M., Bauer J., Bradil M. \& Lassmann H. 2013. Disease-specific molecular events in cortical multiple sclerosis lesions. Brain. 136(6): 1799-1815.

7 Garcia-Segura L.M. \& Melcangi R.C. 2006. Steroids and glial cell function. Glia. 54: 485-498.

8 Garcia-Segura L.M., Naftolin F., Hutchison J.B., Azcoitia I. \& Chowen J.A. 1999. Role of astroglia in estrogen regulation of synaptic plasticity and brain repair. Journal of Neurobiology. 40: 574-584.

9 Garcia-Segura L.M., Wozniak A, Azcoitia I., Rodriguez J.R., Hutchison R.E. \& Hutchison J.B. 1999. Aromatase expression by astrocytes after brain injury: implications for local estrogen formation in brain repair. Neuroscience. 89: 567-578.

10 Gerstner B., Sifringer M., Dzietko M., Schüller A., Lee J., Simons S., Obladen M., Volpe J.J., Rosenberg P.A. \& Felderhoff-Mueser U. 2007. Estradiol attenuates hyperoxia-induced cell death in the developing white matter. Annals of Neurology. 61: 562-573.

11 Ghoumari A.M., Ibanez C., El-Etr M., Leclerc P., Eychenne B., O’Malley B.W., Baulieu E.E. \& Schumacher M. 2003. Progesterone and its metabolites increase myelin basic protein expression in organotypic slices cultures of rat cerebellum. Journal of Neurochemistry. 86: 848-859.

12 Gonzalez Deniselle M.C., Lopez-Costa J.J., Saavedra J.P., Pietranera L., Gonzalez S.L., Garay L., Guennoun R., Schumacher M. \& De Nicola A.F. 2002. Progesterone neuroprotection in the wobbler mouse, a genetic model of spinal cord motor neuron disease. Neurobiology of Disease. 11: 457-468.

13 Hutchison J.B. 1991. Hormonal control of behaviour: steroid action in the brain. Current Opinion in Neurobiology. 1: $562-570$

14 Ito Y., Akao Y., Shimazawa M., Seki N., Nozawa Y. \& Hara H. 2007. Lig-8, a highly bioactive lignophenol derivative from bamboo lignin, exhibits multifaceted neuroprotective activity. CNS Drug Reviews. 13(3): 296-307.

15 Kipp M., Karakaya S., Johann S., Kampmann E., Mey J. \& Beyer C. 2007. Oestrogen and progesterone reduce lipopolysaccharide-induced expression of tumour necrosis factor-alpha and interleukin-18 in midbrain astrocytes. Journal of Neuroendocrinology. 19: 819-822.

16 Koenig H.L., Schumacher M., Ferzaz B., Thi A.N., Ressouches A., Guennoun R., Jung-Testas I., Robel P., Akwa Y. \& Baulieu E.E. 1995. Progesterone synthesis and myelin formation by Schwann cells. Science. 68(5216): 1500-1503.

17 Kume T., Katsuki H. \& Akaike A. 2004. Endogenous factors regulating neuronal death induced by radical stress. Biological and Pharmaceutical Bulletin. 27(7): 964-967.

18 Lassmann H. 2014. Mechanisms of white matter damage in multiple sclerosis. Glia. 62(11): 1816-1830.

19 Lephart E.D. 1996. A review of brain aromatase cytochrome P450. Brain Research Reviews. 22: 1-26.

20 MacLusky N.J. \& Naftolin F. 1981. Sexual differentiation of the central nervous system. Science. 211: 1294-1302.

21 Micevych P.E., Chaban V., Ogi J., Dewing P., Lu J.K. \& Sinchak K. 2007. Estradiol stimulates progesterone synthesis in hypothalamic astrocyte cultures. Endocrinology. 148(2): 782-789.

22 Morell P., Barrett C.V., Mason J.L., Toews A.D., Hostettler J.D., Knapp G.W. \& Matsushima G.K. 1998. Gene expression in brain during cuprizone-induced demyelination and remyelination. Molecular and Cellular Neurosciences. 12: 220-227.

23 Peter A., Markus K., Akvile N., Sonja J., Tim C., Alena B., Zoltan B., Samuel K. \& Cordian B. 2009. 17b-estradiol and progesterone prevent cuprizone provoked demyelination of corpus callosum in male mice. Glia. 57: 807-814. 
24 Peterson R.S., Saldanha C.J. \& Schlinger B.A. 2001. Rapid upregulation of aromatase mRNA and protein following neural injury in the zebra finch (Taeniopygia guttata). Journal of Neuroendocrinology. 13: 317-323.

25 Schobesberger H. \& Peham C. 2002. Computerized detection of supporting forelimb lameness in the horse using an artificial neural network. Veterinary Journal. 163(1): 77-84.

26 Schumacher M., Guennoun R., Robert F., Carelli C., Gago N., Ghoumari A., Gonzalez Deniselle M.C., Gonzalez S.L., Ibanez C., Labombarda F., Coirini H., Baulieu E.E. \& De Nicola A.F. 2004. Local synthesis and dual actions of progesterone in the nervous system: neuroprotection and myelination. Growth Hormone and IGF Research. 14: 18-33.

27 Sinchak K., Mills R.H., Tao L., LaPolt P., Lu J.K. \& Micevych P. 2003. Estrogen induces de novo progesterone synthesis in astrocytes. Developmental Neurosciences. 25(5): 343-348.

28 Skripuletz T., Hackstette D., Bauer K., Gudi V., Pul R., Voss E., Berger K., Kipp M., Baumgärtner W. \& Stangel M. 2012. Astrocytes regulate myelin clearance through recruitment of microglia during cuprizone-induced demyelination. Brain. 136(1): 147-167.

29 Stein D.G. 2001. Brain damage, sex hormones and recovery: a new role for progesterone and estrogen? Trends in Neurosciences. 24: 386-391.

30 Takao T., Flint N., Lee L., Ying X., Merrill J. \& Chandross K.J. 2004. 17beta-estradiol protects oligodendrocytes from cytotoxicity induced cell death. Journal of Neurochemistry. 89: 660-673.

31 Taylor L.C., Gilmore W., Jenny P., Ting Y. \& Matsushima G.K. 2010. Cuprizone induces similar demyelination in male and female C57BL/6 mice and results in disruption of the estrous cycle. Journal of Neurosciences Research. 88: 391-402.

32 Tiwari-Woodruff S., Morales L.B., Lee R. \& Voskuhl R.R. 2007. Differential neuroprotective and antiinflammatory effects of estrogen receptor (ER)alpha and ERbeta ligand treatment. Proceedings of the National Academy of Sciences of the United States of America. 104(37): 14813-14818.

33 Wang Y., Cheng X., He Q., Zheng Y., Kim D.H., Whittemore S.R. \& Cao Q.L. 2011. Astrocytes from the Contused Spinal Cord Inhibit Oligodendrocyte Differentiation of Adult Oligodendrocyte Precursor Cells by Increasing the Expression of Bone Morphogenetic Proteins. Journal of Neuroscience. 31(16): 6053-6058.

34 Yarim M., Gulbahar M.Y., Guvenc T., Karahan S., Harada N., Kabak Y.B. \& Karayigit M.O. 2010. Aromatase expression in the cerebellum of the dog infected with canine distemper virüs. Berliner und Müncherier Tieraztliche Wochenschrift. 123: 301-306.

35 Yarim G.F.,Yarim M., Ciftci G. \& Karayigit M.O. 2013. Deneysel demiyelinasyon ve remiyelinasyonda merkezi sinir sisteminin miyelin temel protein profili. Türk Biyokimya Dergisi. 38(4): 451-456.

36 Zawadzka M., Rivers L.E., Fancy S.P.J., Zhao C., Tripathi R., Jamen F., Young K., Goncharevich A., Pohl H., Rizzi M., Rowitch D.H., Kessaris N., Suter U., Richardson W.D. \& Franklin R.J. 2010. CNS-Resident Glial Progenitor/Stem Cells Produce Schwann Cells as well as Oligodendrocytes during Repair of CNS Demyelination. Cell Stem Cell. 6(6): 578-590.

37 Zurbriggen A., Schmid I., Graber H.U. \& Vandevelde M. 1998. Oligodendroglial pathology in canine distemper. Acta Neuropathologica. 95(1): 71-77. 